\title{
Association between moment of the undergraduate course and cardiovascular risk factors in university students
}

\author{
Guilherme da Silva Gasparotto ${ }^{1}$ \\ Lívia Pimenta Renó Gasparotto ${ }^{2}$ \\ Laila Miranda Rossi ${ }^{3}$ \\ Natália Boneti Moreira ${ }^{4}$ \\ Maicon de Siqueira Bontorin ${ }^{5}$ \\ Wagner de Campos ${ }^{6}$
}

\begin{abstract}
Aim: This study aimed to verify the association between moment of the undergraduate course and cardiovascular risk factors in a representative sample of university students Methods: A total of 1,599 university students (1,197 freshmen and 402 seniors) were investigated for the following risk factors: insufficient practice of physical activity, tobacco and alcohol consumption, poor eating habits, excess body weight, increased waist circumference and elevated arterial pressure. Information regarding the practice of physical activity were obtained using the International Physical Activity Questionnaire (IPAQ) instrument, the behaviors using the Youth Risk Behavior Surveillance, and the socio-environmental information using the methodology of the Associação Brasileira de Empresas de Pesquisa (Brazilian Association of Research Companies). Results: A significantly higher probability of presenting the following risk factors was verified among the senior students: insufficient practice of physical activity, smoked, consumed alcohol or drank alcohol in excess within the last thirty days. Conclusion: The results suggest that students closer to the end of the undergraduate course show a higher possibility of presenting some cardiovascular risk factors than those just entering the university environment. Therefore, prevention programs and health promotion during the undergraduate course should be investigated.
\end{abstract}

Descriptors: Risk Factors; Life Style; Students.

\footnotetext{
${ }^{1}$ Doctoral student, Universidade Federal do Paraná, Curitiba, PR, Brazil.

2 Doctoral student, Universidade Estadual de Campinas, Campinas, SP, Brazil.

3 Physical Educator.

${ }^{4}$ Master's student, Departamento de Educação Física, Universidade Federal do Paraná, Curitiba, PR, Brazil.

${ }^{5}$ Master's student, Facultad de Formación del Profesorado, Universidad de Barcelona, Spain.

${ }^{6}$ PhD, Associate Professor, Departamento de Educação Física, Universidade Federal do Paraná, Curitiba, PR, Brazil.
}

Corresponding Author:

Guilherme da Silva Gasparotto

Rua Ildefonso Stockler de França, 414, Apto. 13

Bairro: Novo Mundo

CEP: 81020-040, Curitiba, PR, Brasil

E-mail: guilhermegptt@gmail.com 


\section{Introduction}

It is known that the majority of deaths worldwide are caused by cardiovascular diseases (CVDs) and various risk factors (RFs) may influence the development of this type of pathology. These factors can be observed in various populations, including university students ${ }^{(1-3)}$. In this group, the literature indicates the presence of relevant RFs, such as the increase of insufficient physical activity, consumption of substances such as tobacco and alcohol, and bad eating habits. These factors could also influence the development of other health problems related to metabolic and cardiovascular health ${ }^{(4-5)}$.

Studies suggest that the emergence or intensification of cardiovascular RFs in university students can be related to the length of exposure to the undergraduate course environment ${ }^{(3,6)}$. Other studies also mention that the intensity of this association may be influenced by certain socio-environmental factors, such as gender, marital status, period of study, type of residence, and socioeconomic status ${ }^{(7)}$.

Some studies only present the prevalence of cardiovascular RFs in university students, while other authors present comparisons analyses between undergraduate course moments. However, the association between the moment of the undergraduate course in which the students are and these factors has not been well explored(3,6). Among studies that investigated such associations, some can be seen to have used a sample that was not representative of the population, making it difficult to draw conclusions regarding the results, furthermore, few studies can be found that use samples of freshmen and senior students for this analysis(3,8). In this context, obtaining a large probabilistic sample of university students, stratified into groups of freshmen and seniors, to perform the analysis of association between moments of the undergraduate course and cardiovascular RFs could help identify individuals vulnerable to exposure to the undergraduate course period. Furthermore, this would also contribute to healthcare professionals being able to determine prevention and promotion strategies, as this type of study is the first step in defining these actions. Given the above, the aim of this study was to investigate the association between the moment of the undergraduate course and cardiovascular risk factors in a representative sample of students from a university in southern Brazil.

\section{Method}

\section{Population and Sample}

In 2011, the Federal University of Paraná had 5,059 freshmen and 1,582 enrolled in the final year of their respective courses, with a total target population for the study of 6, 641 students. For the sample determination the calculator from the Epi Info program, developed by Centers for Disease Control and Prevention (CDC), was used, taking into consideration: a confidence level of $95 \%$ and sample power of $80 \%$. The prevalence of being overweight $\left(B M I \geq 25 \mathrm{~kg} / \mathrm{m}^{2}\right.$ ) in active and insufficiently active university students was taken from that published in a similar study ${ }^{(9)}$. A correction of the sample (deff) of 1.5 was adopted ${ }^{(10)}$, plus $10 \%$ for possible data losses, giving the $n$ needed of 1,577 students. This value was distributed proportionally according to the moment of graduation, the area of study (Humanities, Exact and Biological sciences) and the study period (day and evening). The next step was the random selection of the groups, which were evaluated in their entirety.

\section{Instruments and Procedures}

The socioeconomic status was estimated using the methodology of the Associação Brasileira de Empresas de Pesquisa (Brazilian Association of Research Companies) $(A B E P)^{(11)}$, in which the classifications suggested were grouped into "high" socioeconomic status (A1, A2, B1, B2) and "low" socioeconomic status (C1, C2, D and E). The IPAQ (International Physical Activity Questionnaire) was used to obtain the level of physical activity ${ }^{(12)}$, classifying students as Active and Insufficiently Active according to the WHO recommendation of 150 minutes or more of moderate/vigorous physical activity (MVPA) weekly(13). The behaviors of smoking, drinking and eating habits, were investigated through specific questions contained in the YRBS-C (Youth Risk Behavior Surveillance), developed by the CDC (Centers for Disease Control and Prevention), previously validated and used in another study with Brazilian university students ${ }^{(14)}$.

Regarding the habit of smoking, the students were asked, on how many days within the last thirty they had used tobacco. They were classified as smokers if they reported having smoked during this period. In relation to the consumption of alcohol, the students were asked on how many days within the last thirty they had consumed alcohol and how often they had consumed five or more drinks on the same occasion. They were 
classified as drinkers if they had consumed alcohol within this period. Regarding eating habits, the students were asked whether on the day before the survey they had consumed fruit, salad greens, vegetables, snacks (chips or similar), cakes/pies or candies in general and the amount consumed. The consumption of fruits followed the cutoff of three or more servings per day, this same amount was defined as the cutoff point for portions of salad greens and/or vegetables ${ }^{(15)}$.

Anthropometric measurements were performed according to previously described methods ${ }^{(16)}$. Information regarding weight and height was collected to calculate the BMI (Body Mass $/ \mathrm{Height}^{2}$ ), with which the students were classified as normal weight, below $\mathrm{BMI}<25 \mathrm{~kg} / \mathrm{m}^{2}$ or excess weight, BMI $\geq 25 \mathrm{~kg} / \mathrm{m}^{2(1)}$. For the height measurement a metal anthropometric tape attached to the wall with a scale of $0.1 \mathrm{~m}$ intervals was used. The measurement was carried out barefoot, with the weight distributed between the feet, and the arms relaxed, with the students instructed to remain as upright as possible. The determination of body weight was performed using a G-TECH digital balance with a resolution of $0.1 \mathrm{~kg}$. The students were barefoot and were instructed to distribute the body weight between both feet when on the scales. The measurement of the waist circumference was also performed using an anthropometric metallic tape with a $0.1 \mathrm{~cm}$ scale, taken at the narrowest part of the torso, as seen from the anterior aspect, at the midpoint between the last rib and the iliac crest, using the cutoff points suggested by the $\mathrm{WHO}^{(1)}$ : $\geq 94 \mathrm{~cm}$ for men and $\geq 80 \mathrm{~cm}$ for women.

Systolic (SBP) and diastolic blood pressure (DBP) were measured using the auscultatory method, on the left arm of each evaluated individual, with a stethoscope and analog sphygmomanometer (BD brand) calibrated a week prior to the start of data collection, which lasted five months. The students spent at least five minutes at rest, sitting with their legs uncrossed, feet flat on the floor and leaning back in the chair prior to the measurement. The arm was positioned at heart level with the palm facing upward and the elbow slightly flexed. The cuff of the sphygmomanometer was positioned about 2 to $3 \mathrm{~cm}$ from the cubital fossa, and the bell of the stethoscope over the brachial artery without excessive compression. Blood pressure was considered high when either the SBP or the DBP, or both, had values at or above the cutoff points of $140 \mathrm{mmHg}$ for the SBP and $90 \mathrm{mmHg}$ for the $\mathrm{DBP}^{(1)}$.

All the responses and measurements were obtained within approximate 45 minutes, during the class period, after prior authorization from each department for the entrance of the researchers into the classroom. The study was approved by the Human Research Ethics Committee of the Health Sciences sector, Federal University of Paraná, in agreement with resolution No. 196/1996 of the National Health Council, under registration CEP/SD: 1043.168.10.11.

\section{Statistical Analysis}

Data normality was verified through the Kolgomorov-Smirnov test. The data were described through the analysis of the prevalence of the variables. The Prevalence Ratio (PR) was analyzed, through Poisson regression with robust analysis, to verify the probability of the senior students presenting cardiovascular risk factors in relation to the freshmen. For the adjustment it was suggested that the intervening variables be included in the model: gender, marital status, study period (day or evening), type of residence (with parents or not), and socioeconomic status. The significance level stipulated for the analyzes was $p<0.05$. All analyzes were performed using the SPSS 18.0 statistical program.

\section{Results}

Of the 6,541 individuals eligible to compose the sample, 1,631 students were evaluated, distributed between the three study areas, humanities, exact and biological sciences. After removal of incomplete or incorrectly completed questionnaires the total was 1,599 students, with 1,197 freshmen and 402 seniors.

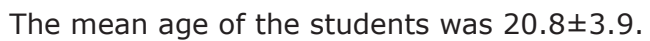

The description of the prevalence of socioenvironmental factors for the sample is shown in Table 1 below.

Table 1 - Prevalence of socio-environmental factors

\begin{tabular}{|c|c|c|c|c|c|c|}
\hline \multirow{2}{*}{ Variables } & \multicolumn{3}{|c|}{ Seniors } & \multicolumn{3}{|c|}{ Freshmen } \\
\hline & $\mathbf{N}$ & $\%$ & $\mathrm{Cl} 95 \%$ & $\mathrm{~N}$ & $\%$ & $\mathrm{Cl} 95 \%$ \\
\hline \multicolumn{7}{|l|}{ Gender } \\
\hline Male & 212 & 52.7 & $42.1-52.1$ & 599 & 50 & $47.3-52.9$ \\
\hline Female & 190 & 47.3 & $48.1-58.2$ & 598 & 50 & $47.1-52.7$ \\
\hline
\end{tabular}


Table 1 - (continuation)

\begin{tabular}{|c|c|c|c|c|c|c|}
\hline \multirow{2}{*}{ Variables } & \multicolumn{3}{|c|}{ Seniors } & \multicolumn{3}{|c|}{ Freshmen } \\
\hline & $\mathbf{N}$ & $\%$ & $\mathrm{Cl} 95 \%$ & $\mathbf{N}$ & $\%$ & Cl 95\% \\
\hline \multicolumn{7}{|l|}{ Marital status } \\
\hline Single & 373 & 92.8 & $90.1-95.3$ & 1112 & 92.9 & $91.3-94.2$ \\
\hline Married & 29 & 7.2 & $4.7-10$ & 85 & 7.1 & $5.8-8.7$ \\
\hline \multicolumn{7}{|l|}{ Study Period } \\
\hline Day & 269 & 66.9 & $61.9-71.6$ & 894 & 74.7 & $72.3-77$ \\
\hline Evening & 133 & 33.1 & $28.4-38.1$ & 303 & 25.3 & $23-27.7$ \\
\hline \multicolumn{7}{|l|}{ Type of Residence } \\
\hline Parent's Home & 262 & 65.2 & $60.4-69.9$ & 845 & 70.6 & $68.2-73$ \\
\hline Share residence or Live Alone & 140 & 34.8 & $30.1-39.6$ & 352 & 29.4 & $27-31.8$ \\
\hline \multicolumn{7}{|l|}{ Socioeconomic Level } \\
\hline High & 309 & 76.9 & $72.6-80.8$ & 899 & 75.1 & $72.4-77.6$ \\
\hline Low & 93 & 23.1 & $19.2-27.4$ & 298 & 24.9 & $22.4-27.6$ \\
\hline
\end{tabular}

CI - Confidence Interval.

The prevalence ratio analysis showed a relationship between the moment of the undergraduate course of the students and some of the cardiovascular risk factors studied. It was observed that the seniors had a higher probability of having smoked in the thirty days preceding the survey, compared to the freshmen. The same was the case for the variables related to alcohol consumption. In addition to these behaviors, the insufficient practice of physical activity was more common among the seniors compared to the freshmen. The prevalence values and PR adjusted for the moment of the undergraduate course and cardiovascular risk factors are shown in table 2 below.

Table 2 - Prevalence and prevalence ratio of the cardiovascular risk factors between moments

\begin{tabular}{|c|c|c|c|c|c|}
\hline Variables & $\mathbf{N}$ & $\%(\mathrm{Cl} 95 \%)$ & PR & $\mathrm{Cl} 95 \%$ & $\mathbf{p}$ \\
\hline \multicolumn{6}{|l|}{ MVPA<150 minute/week } \\
\hline Seniors & 240 & $59.7(54.5-64.4)$ & 1.15 & $1.11-1.32$ & $<0.05$ \\
\hline Freshmen & 630 & $52.1(50.1-55.7)$ & 1 & & \\
\hline \multicolumn{6}{|l|}{ Smoked } \\
\hline Seniors & 65 & $16.2(12.7-19.9)$ & 1.52 & $1.21-2.09$ & $<0.01$ \\
\hline Freshmen & 115 & $9.4(8.1-11.4)$ & 1 & & \\
\hline \multicolumn{6}{|l|}{ Consumed alcohol } \\
\hline Seniors & 307 & $76.4(72.4-80.6)$ & 1.24 & $1.15-1.34$ & $<0.01$ \\
\hline Freshmen & 726 & $60.7(58.3-63.5)$ & 1 & & \\
\hline \multicolumn{6}{|l|}{ Consumed alcohol in excess } \\
\hline Seniors & 219 & $54.5(49.8-59.7)$ & 1.67 & $1.46-1.91$ & $<0.01$ \\
\hline Freshmen & 420 & $35.2(32.7-38.1)$ & 1 & & \\
\hline \multicolumn{6}{|c|}{ Consumed 3 or more portions of fruits } \\
\hline Seniors & 35 & $8.7(6.1-11.7)$ & 1.12 & $0.74-1.59$ & 0.67 \\
\hline Freshmen & 91 & $7.6(6.2-9.1)$ & 1 & & \\
\hline \multicolumn{6}{|c|}{ Consumed 3 or more portions of salads or vegetables } \\
\hline Seniors & 69 & $17.2(13.9-21.1)$ & 0.89 & $0.69-1.15$ & 0.38 \\
\hline Freshmen & 246 & $20.6(18.2-23.1)$ & 1 & & \\
\hline \multicolumn{6}{|l|}{ Consumed snacks } \\
\hline Seniors & 141 & $35.1(30.1-39.6)$ & 1.03 & $0.87-1.22$ & 0.71 \\
\hline Freshmen & 412 & $34.5(32.1-37.3)$ & 1 & & \\
\hline \multicolumn{6}{|l|}{ Consumed candies } \\
\hline Seniors & 265 & $65.9(61.2-70.6)$ & 0.95 & $0.87-1.03$ & 0.23 \\
\hline Freshmen & 834 & $69.9(67.1-72.3)$ & 1 & & \\
\hline \multicolumn{6}{|l|}{ Overweight/Obese } \\
\hline Seniors & 118 & $29.4(24.6-33.6)$ & 1.04 & $0.86-1.24$ & 0.72 \\
\hline
\end{tabular}


Table 2 - (continuation)

\begin{tabular}{|c|c|c|c|c|c|}
\hline Variables & $\mathbf{N}$ & $\%(\mathrm{Cl} 95 \%)$ & PR & CI $95 \%$ & p \\
\hline Freshmen & 295 & $24.7(22.5-27.2)$ & 1 & & \\
\hline \multicolumn{6}{|l|}{ Increased waist circumference } \\
\hline Seniors & 39 & $9.7(8.3-11.7)$ & 0.81 & $0.57-1.15$ & 0.24 \\
\hline Freshmen & 119 & $10.1(7.1-12.7)$ & 1 & & \\
\hline \multicolumn{6}{|l|}{ High arterial pressure } \\
\hline Seniors & 42 & $10.4(7.5-13.4)$ & 0.89 & $0.64-1.26$ & 0.53 \\
\hline Freshmen & 110 & $9.2(7.6-10.8)$ & 1 & & \\
\hline
\end{tabular}

MVPA - Moderate-Vigorous Physical Activity; PR - Prevalence Ratio; CI - Confidence Interval

\section{Discussion}

The literature highlights the relevance of studying cardiovascular risk factors in university students, with it being important to understand how these factors behave within this population, as this may change according to the environment and length of exposure ${ }^{(3,6)}$.

In the present study the probability of observing a student smoker was significantly higher in the seniors, when compared to the freshmen ( $P R=1.52 ; \mathrm{CI}: 1.21-$ 2.09). Joining the university can provide a sense of independence coupled with the need to be included in the new social environment ${ }^{(17)}$. These factors combined with an increased exposure to tobacco consumption possibilities, due to frequent parties and student gatherings sponsored by the student communities, may promote increased consumption of these substances, as these events help in the socialization of students, leading to greater contact with these products. From this perspective, other authors, through the opinions of the students themselves, previously perceived the common reasons for adhering to smoking to be: the influence of friends, the new environment and, in the case of men, the self-confidence to be accepted into the group (17-18).

In the present study, the probability of observing a student who consumed alcohol between the groups was also significantly higher in the senior students, compared to the freshmen ( $P R=1.24 ; C I: 1.15-1.34)$, as was the behavior of drinking alcohol in excess, however, with a more expressive value ( $P R=1.67 ; C I$ : 1.46-1.91). Alcohol consumption among young people is behavior often approached by youth health researchers, not only due to the problems that may be caused from a biological perspective, but also because of the social losses induced by excessive alcohol consumption in this age group ${ }^{(2,19)}$. The arguments that justify the difference in tobacco consumption between the moments of the undergraduate course can also be applied to the higher alcohol consumption among senior university student compared with the freshmen, therefore, many times these two appear related ${ }^{(2,20)}$. Greater socialization and increased exposure may both be determinants for increases in these behaviors(21-22). One study reinforces this position, using a sample of Bolivian university students, by showing that the freshman students selfreported that the motivation for alcohol consumption was the social context in which they lived, which could lead to increased participation in events that facilitate this behavior ${ }^{(23)}$.

Another RF that was significantly associated with the moment of the undergraduate course was the practice of weekly MVPA. The PR of insufficient activity was higher for the freshman students than for the seniors ( $P R=1.15 ; C I: 1.11-1.32)$. The literature is unclear regarding the association of the moment of the undergraduate course with the practice of MVPA, and presents contradictory results. Some studies suggest a greater likelihood of seniors being more active than freshmen ${ }^{(3,21)}$. However, similar to the data found in the present study, another study showed higher chances $(O R=1.73)$ of seniors presenting low levels of physical activity compared to freshmen ${ }^{(24)}$. Researchers have also observed no differences between the level of physical activity in the moments of the graduation ${ }^{(6,25)}$. In the present study, it is possible that the increase in the time required to complete academic and extracurricular activities, and, in many cases, the need to work during the academic education can negatively influence the time spent doing physical activities.

In some countries it is possible to verify the commitment of Institutions to develop projects that facilitate the engagement of students in physical activity programs, such as the National Association of Sport and Physical Education (NASPE) and the College and University Physical Education Council (CUPEC) which have published positions in favor of including physical activity programs as part of the curriculum in North American universities, in order to combat potential 
behaviors that favor health risk factors in the students ${ }^{(26)}$. In Brazil a discipline that involves physical exercise is not mandatory in the university curriculum and there is a lack of physical activity programs for this population, with the practice of this type of activity being up to the undergraduate students themselves, which could justify the small proportion of individuals regularly practicing MVPA in this population.

The variables related to eating habits, excess body weight, increased waist circumference and high blood pressure were not significantly associated with the moment of the graduation. Regarding the eating habits, the consumption of fruit, vegetables and salads also appeared low and similar. It appears that this behavior does not undergo major changes in relation to exposure to the academic environment. Previous analyzes of this relationship have also revealed that the consumption of fruits, salads and vegetables was very similar between the first and last college semesters, and did not demonstrate an association with the moment of the undergraduate course ${ }^{(21)}$.

Similar to the intake of fruit, vegetables and salads, that of snacks and candies did not demonstrate an association with the moment of the graduation, showing similarity between the groups. Another study also found no association between the moment of the undergraduate course and the consumption of candies and snacks among North American students. However, in the present study, the consumption of these foods was high for both groups, which would justify preventive actions to promote healthy eating from the first year of the graduation ${ }^{(27)}$. It can be suggested that, due to the lack of observed differences in eating habits between the seniors and the freshmen, the BMI and WC values should not significantly change during the graduation, to the point of demonstrating a significant association in the analysis, which was the case in the present study, as previously presented.

The lack of significant association between the moment of the undergraduate course and high arterial pressure may be related to the low mean age of these

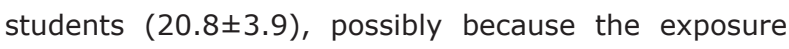
to the insufficient practice of MVPA, as well as other risk behaviors and levels of being overweight or obese may not have been sufficient to alter arterial pressure. There was a relatively low number of students with high blood pressure at the time of the study, as is the case in other studies with samples of university students(28-29). However, preventive measures against these factors appear to be relevant since it has been stated in previous studies that it is likely that university students who present these factors develop cardiovascular diseases in

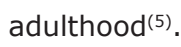

It is possible to identify some limitations, such as the self-reported measures of the practice of MVPA and of risk behavior and consequently the dependence upon the respondents for the veracity of information. However, the strong points of the study can be highlighted, which were that it used a large representative sample, stratified by moments of the graduation, areas of knowledge and school periods, which adds strength to the analyses.

\section{Conclusion}

From the data obtained, this study shows that among freshman and graduate students the probability of smoking, consuming alcohol, and abusing alcohol on a single occasion within the last thirty days, was higher among the seniors. In addition to these behaviors, there was also a higher probability that the senior students insufficiently practiced physical activities compared to the freshmen. The moment of the undergraduate course was not associated with the variables related to eating habits, excess weight or high arterial pressure.

These findings suggest the need for awareness programs for students, regarding the risk factors to which they are exposed during the graduation, assisting in discouraging those who have never experimented with tobacco and alcohol, as well as the reduction or definitive cessation of this type of behavior in those that do use these substances. The development is also suggested of actions for increasing MVPA and improving eating habits during the graduation, such as institutional policies, seeking opportunities for physical activities and knowledge about the risk factors to health. More ambitiously, it draws attention to the question of the incorporation of a discipline into the study routine, which would offer guidance for university students related health habits during this period and for the rest of their lives.

\section{References}

1. World Health Organization. Prevention of cardiovascular disease: guidelines for assessment and management of total cardiovascular risk. World Health Organization, Geneva, Switzerland, 2007.

2. Hvidtfeldt UA, Tolstrup JS, Jakobsen MU, Heitmann BL, Gronbaek M, O'Reilly $E$, et al. Alcohol Intake and Risk of Coronary Heart Disease in Younger, Middle-Aged, and Older Adults. Circulation. 2010;121:1589-97. 
3. Vankim NA, Laska MN, Ehlinger E, Lust K, Story M. Understanding young adult physical activity, alcohol and tobacco use in community colleges and 4-year post-secondary institutions: A cross-sectional analysis of epidemiological surveillance data. BMC Pub Health. 2010;10:2008-17.

4. Wechsler H, Rigotti NA, Gledhill-Hoyt J, Lee, H. Increased Levels of Cigarette Use Among College Students. JAMA. 1998; 280(19):1673-8.

5. Sahi T, Paffenbarger RS, Hsieh C, Lee IM. Body Mass Index, Cigarette Smoking, and Other Characteristics as Predictors of Self-Reported, Physician-Diagnosed Gallbladder Disease in Male College Alumni. Am J of Epidemiol. 1998;147(7):644-51.

6. Racette SB, Deusinger SS, Strube MJ, Highstein GR, Deusinger $\mathrm{RH}$. Changes in Weight and Health Behaviors from Freshman through Senior Year of College. J of Nutr Educ Behav. 2008;40(1):39-42.

7. Silva LVER, Malbergier A, Stempliuk VA, Andrade AG. Fatores associados com uso de drogas e alcool entre universitários. Rev Saúde Pub. 2006;40(2):1-8.

8. Han JL, Dinger MK, Hull HR, Randall NB, Heesch KC, Fields DA. Changes in Women's Physical Activity During the Transition to College. Am J of Health Educ. 2008;39(4):194-9.

9. Ribeiro M, Fernandes A. Prática de actividade física em jovens alunos do ensino superior público do concelho de Bragança. Promoção da saúde e actividade fisica: Contr Des Hum, 2010;1:534-44.

10. Carvalho AMC, Araújo TME. Fatores associados à cobertura vacinal em adolescentes. Acta Paul Enferm. 2010;23(6):796-802.

11. ABEP. Associação Brasileira de Empresas de Pesquisa: Critério de Classificação Econômica Brasil 2008. [acesso em 29/11/2010]. Disponível em www.abep.org/novo/ FileGenerate. ashx ?id $=250$

12. Pardini R, Matsudo S, Araújo T, Matsudo V, Andrade E, Braggion Get al.. Validação do International Physical Activity Questionaire (IPAQ-6) - Estudo Piloto com jovens adultos brasileiros. Rev Bras Cie Mov. 2001;9(3):45-51. 13. World Health Organization. Global recommendations on physical activity for health. World Health Organization, Geneva, Switzerland, 2010.

14. Pillon, SC, O'Brien B, Piedra C, Ketty A. The relationship between drugs use and risk behaviors in brazilian university students. Rev. Latino-Am. Enfermagem. 2005;13(spe2):1169-76.

15. Dietary Guidelines for Americans 2010: Implications for Cardiovascular Disease. Curr Ater Rep. 2011;13(6):499-507.
16. Tarnus E, Bourdon E. Anthropometric evaluations of body composition of undergraduate students at the University of La Réunion. 2006; Advan in Physiol Edu; 30:248-53.

17. Baer JS. Student Factors: Understanding Individual Variation in College Drinking. J of Stud Alc. 2002;(Supp14):40-53.

18. Sánchez-Hernández CM, Pillon SC. Smoking among college students: characterization of use in the students' perspective. Rev. Latino-Am. Enfermagem. 2011;19(spe):730-7.

19. Ortega-Pérez, CA, Costa-Júnior $M L$, Vasters GP. Epidemiological profile of drug addiction in college students. Rev. Latino-Am. Enfermagem. 2011;19(spe):665-72.

20. Halperin AC, Smith SS, Heiligenstein E, Brown D, Fleming MF. Cigarette smoking and associated health risks among students at five universities. Nicot \& Tobac Res. 2010;12(2):96-104.

21. Franca C, Colares V. Estudo comparativo de condutas de saúde entre universitários do início e final do curso. Rev Saúde Pub. 2008;42(3):420-7.

22. Morales $B N$, Plazas $M$, Sanchez $R$, Ventura CAA. Risk and protection factors related to the consumption of psychoactive substances in undergraduate nursing students. Rev. Latino-Am. Enfermagem. 2011;19(spe):673-83.

23. Balda-Cabello N, Silva EC. Bolivian university students' view of alcohol use in the university context. Rev. Latino-Am. Enfermagem. 2011;19(spe):699-706.

24. Fontes ACD, Vianna RPT. Prevalência e fatores associados com o baixo nível de atividade física entre estudantes de uma universidade pública do Nordeste Brasil. Rev Bras Epidemio. 2009;12(1):20-9.

25. Silva KS, Nahas MV, Hoefelmann LP, Lopes AS, Oliveira ES. Associação entre atividade física, Índice de Massa Corporal e sedentarismo em adolescentes. Rev Bras Epidemio. 2008;11(1):159-68.

26. National Association of Sport and Physical Education (NASPE); College and University Physical Education Concil (CUPEC). College/University Physical Activity Instruction Programs. A Critical Piece in the Education of Young Adults: A Position Paper from the National Association for Sport and Physical Education. J Phys Sport Educ. 2007;20(6):1-4.

27. Nelson MC, Larson NI, Barr-Anderson D, NeumarkSztainer D, Story M. Disparities in Dietary Intake, Meal Patterning, and Home Food Environments Among Young Adult Nonstudents and 2- and 4-Year College Students. Am J of Pub Health. 2009;99(7):1216-9. 
28. Martins MCC, Ricarte IF, Rocha CHL, Maia RB, Silva VB, Veras AB, Souza Filho MD. Pressão Arterial, Excesso de Peso e Nível de Atividade Física em Estudantes de Universidade Pública. Arq Bras Cardiol. 2010;95(2):192-9.

29. Oviedo G, Morón de Salim A, Santos I, Sequera S, Soufrontt G, Suárez P, Arpaia A. Factores de riesgo de enfermedades crónicas no transmisibles en Estudiantes de la carrera de Medicina. Universidad de Carabobo, Venezuela. Año 2006. Nutr Hosp. 2008;23(3):288-93. 